cetuximab versus FOLFIRI plus bevacizumab as first-line treatment for patients with metastatic colorectal cancer (FIRE-3): a randomised, open-label, phase 3 trial", Lancet Oncol, 15(10), tr. 1065-75.

2. G. Kim, E. J. Jung, C. G. Ryu và các cộng sự. (2013), "Usefulness of carcinoembryonic antigen for monitoring tumor progression during palliative chemotherapy in metastatic colorectal cancer", Yonsei Med J, 54(1), tr. 116-22.

3. G. A. Colloca, A. Venturino và D. Guarneri (2019), "Carcinoembryonic antigen reduction after medical treatment in patients with metastatic colorectal cancer: a systematic review and metaanalysis", Int J Colorectal Dis, 34(4), tr. 657-666.

4. Mangu PB Meyerhardt JA, Flynn PJ et al
(2013), "Follow-up care, surveillance protocol, and secondary prevention measures for survivor of colonrectal cancer: American Society of Clinical Oncology clinical practice guideline endorsement", J Clin Oncol 31, tr. 4465-4470.

5. B. Shinkins, B. D. Nicholson, J. Primrose và các cộng sự. (2017), "The diagnostic accuracy of a single CEA blood test in detecting colorectal cancer recurrence: Results from the FACS trial", PLoS One, 12(3), tr. e0171810.

6. W. S. Wang, J. K. Lin, T. C. Lin và các cộng sự. (2001), "Carcinoembryonic antigen in monitoring of response to systemic chemotherapy in patients with metastatic colorectal cancer", Int J Colorectal Dis, 16(2), tr. 96-101.

\title{
NGÃ VÀ MộT SỐ YẾU Tố LIÊN QUAN TRÊN BỆNH NHẦN CAO TUỔI CÓ LOÃNG XƯO'NG
}

\author{
Nguyễn Thị Thanh Hải ${ }^{1}$, Nguyễn Xuân Thanh ${ }^{2,3}$, Nguyễn Ngọc Tâm²,3 \\ Vũ Thị Thanh Huyền ${ }^{2,3}$, Nguyễn Trung Anh ${ }^{2,3}$
}

\section{TÓM TẮT}

Mục tiêu: xác định tỷ lệ ngã và một số yếu tố liên quan ở người cao tuổi có loãng xương. Phương pháp: nghiên cứu mô tả cắt ngang trên 140 ngưới cao tuổi có loãng xương khám và điều trị bệnh viện Lão Khoa Trung Ương. Kết quả: độ tuổi trung bình của nhóm nghiển cứu là 73,2 $\pm 9,0$ tuổi, tỷ lệ ngã trên người cao tuổi có loãng xương là 34,3\%, trong đó $68,8 \%$ ngã vào buổi sáng, $62,5 \%$ ngã do trượt ngã, $16,7 \%$ ngã khi đứng dậy. Tỷ lệ gãy xương do ngã là 87,5\%. Không có mối liên quan giữa tuổi, giới, hoàn cảnh sống với ngã trên người cao tuổi có loãng xương $(p>0,05)$. Kết luận: Tỷ lệ gãy xương do ngã trên người cao tuổi có loãng xướng rất cao. Do vậy dư phòng ngã trên người cao tuổi có loãng xương là rất quan trong.

Tư'khóa: ngã, loãng xương, người cao tuổi, gãy xương.

\section{SUMMARY}

\section{FALLS AND SOME RELATED FACTORS} AMONG OLDER PEOPLE WITH OSTEOPOROSIS

Objectives: to determine the prevalence of falls and some related factors in the elderly with osteoporosis. Methods: A cross-sectional study included of 140 elderly with osteoporosis aged 60 and over who were treated at National Geriatric Hospital. Results: The average age of subjects was $73.2 \pm 9.0$ years old, the prevalence of falls in elderly people with osteoporosis was $34.3 \%$, of which $68.8 \%$ fell in the

${ }^{1}$ Bênh viên Đa khoa Tỉnh Thanh Hóa

${ }^{2}$ Bệnh viện Lão khoa Trung Ương

${ }^{3}$ Trường đai hoc Y Hà Nôi

Chịu trách nhiệm chính: Nguyễn Thị Thanh Hải

Email: nguyenhaibvdkt@gmail.com

Ngày nhân bài: 9.7.2021

Ngày phản biên khoa hoc: 3.9.2021

Ngày duyệt bài: 10.9.2021 morning, $62.5 \%$ falls due to slippage, $16.7 \%$ falls when standing up. The rate of fractures due to falls was $87.5 \%$. There was no relationship between age, gender, living situation with falls in elderly people with osteoporosis. Conclusion: The rate of fractures due to falls in elderly people with osteoporosis is very high. Therefore, it is necessary to prevent falls in the elderly with osteoporosis.

Keywords: fall, osteoporosis, elderly, fracture.

\section{I. ĐĂT VẤN ĐỀ}

Theo tổ chức y tế thế giới ngã là một sự kiện vô tình làm cho cơ thể ngã xuống mặt đất, sàn nhà, hoặc vị trí thấp hơn, ngoại trừ những trường hợp cố ý để thay đổi vị trí của chủ thể trên các đồ nội thất, trên tường hoặc những đối tượng khác [1]. Loãng xương và ngã đều là những vấn đề phổ biến ở người cao tuổi [2].

Loãng xương có liên quan đến những thay đổi trong sự cân bằng, hoạt động thể chất và tâm lý xã hội làm tăng nguy cơ ngã ở người cao tuổi [3]. Người cao tuổi bi loãng xương có tỷ lê và tân suất bị ngã cao hơn so với người không bị loãng xương [2]. Ngã ở người cao tuổi là một vấn đề nghiêm trọng để lai hâuu quả nănng nề cho các cá nhân, gia đình và hệ thống y tế. Tuy nhiên, chúng ta có thể dự phòng được những nguy cơ ngã ở người cao tuổi nói chung và người cao tuổi có loãng xương nói riêng bằng nhiêu biện pháp khác nhau.

Chúng tôi thực hiện nghiên cứu này nhằm xác định tỷ lệ ngã và một số yếu tố liên quan trên đối tượng người cao tuổi có loãng xương, qua đó giúp các nhân viên y tế cũng như những nhà chính sách y tế có thêm những bằng chứng để 
đưa ra những khuyến nghị phù hợp hạn chế tối đa tình trạng ngã ở người cao tuổi nói chung và người cao tuổi có loãng xương nói riêng, góp phần giảm thiểu hậu quả và gánh nặng do ngã gây ra.

\section{II. ĐỐI TƯỢNG VÀ PHƯƠNG PHÁP NGHIÊN CỨU}

Đối tượng nghiên cứu. Bệnh nhân $\geq 60$ tuổi được chẩn đoán có loãng xương đến khám và điều trị tại

Bệnh viện Lão khoa Trung Ương.

Tiêu chuẩn lựa chọn

- Bênh nhân $\geq 60$ tuổi

- Được chẩn đoán loãng xương theo tiêu chuẩn của WHO năm 2001 dựa trên mật độ xương.

- Có khả năng nghe và trá lời được phỏng vân.

- Đồng ý tham gia nghiên cứu

Tiêu chuẩn loại trừ

- Bệnh nhân bị biến chứng cấp tính nặng: Hôn mề nhiễm toan ceton, hôn mê tăng áp lực thẩm thấu, hôn mê do tai biến mạch máu não, đợt cấp mất bù của suy tim, suy gan.

\section{Phương pháp nghiên cứu}

Thiết kế nghiên cứu: Mô tả cắt ngang

Cõ mẫu: Cõ̃ mẫu được tính theo công thức

$$
\mathbf{n}=\frac{\left(z_{1}-\alpha / 2\right)^{2}}{d^{2}} \cdot \mathbf{p} \cdot(\mathbf{1}-\mathbf{p})
$$

Trong đó: $\mathrm{n}$ : cõ mẫu nghiên cứu;

a: mức ý nghĩa thống kê, với $a=0,05$ ( $Z_{1-a / 2}$ $=1,96)$

$p=0,51$ (Tỷ lệ ngã ở người cao tuổi theo kết quả nghiên của Raimunda Beserra Da Silva trên 133 người cao tuổi ( $\geq 60$ tuổi) năm 2010.

$\mathrm{d}=$ sai số mong đợi, $(\mathrm{d}=0,1)$.

Từ công thức trên ta có cỡ mẫu ước tính là 96 bệnh nhân. Trong thời gian thu thập số liệu chúng tôi đã lựa chọn được tất cả 140 người bệnh có đủ tiêu chuẩn lựa chọn tham gia vào nghiên cứu.

Phương pháp chọn mẫu: Chọn mẫu thuận tiện.

Thời gian nghiên cứu: từ tháng 06/2020 đến tháng 09/2021

Công cụ và phương pháp thu thập số liệu

Công cụ thu thập số liệu: mẫu bệnh án nghiên cứu được thiết kế sẵn theo mục tiêu nghiên cứu và hồ sơ quản lý người bệnh tại bệnh viện Lão khoa Trung ương.

Phương pháp thu thập số liệu: phỏng vấn

Biến số- Tiêu chuẩn nghiên cứu:

Chẩn đoán loãng xương theo tiêu chuẩn của Tổ chức Y tế Thế giới (WHO) năm 2001, đo mật độ xương tại cột sống thắt lưng và cổ xương đùi theo phương pháp DXA. Loãng xương khi Tscore dưới-2,5SD.
Ngã được đánh giá thông qua phỏng vấn số lần ngã trong 12 tháng qua của bệnh nhân. Đặc điểm của ngã bao gồm: hoàn cảnh ngã, địa điểm ngã, thời gian ngã, biến chứng gãy xương sau ngã

Các yếu tố liên quan với ngã: nhóm tuổi, hoàn cảnh sống (sống một mình, sống cùng người thân), giới tính

Xử lý số liệu. Số liệu thu được được đưa vào máy tính xử lý bằng phương pháp thống kê y học theo chương trình SPSS 16.0. Sử dụng các thuật toán thống kê để kiểm định. Sử dụng các thuật toán thống kê mô tả thông thường để tính tỷ lệ phần trăm, trung bình. Sự khác biệt có ý nghĩ̃a thống kê với $p<0,05$.

Đạo đức trong nghiên cứu. Nghiên cứu chỉ nhằm mục đích nâng cao sức khỏe cộng đồng và giảm gánh nặng bệnh tật, đảm bảo quyên tự nguyện tham gia nghiên cứu của các đối tượng.

\section{KẾT QUẢ NGHIÊN CỨU}

Bảng 1: Đặc điểm chung ở đôî tượng nghiên cứu (N=140)

\begin{tabular}{|c|c|c|c|}
\hline \multicolumn{2}{|c|}{ Đặc điểm } & \multirow{2}{*}{$\begin{array}{c}\text { Tần số } \\
\text { (n) }\end{array}$} & \multirow{2}{*}{$\begin{array}{l}\text { Tỉ lề } \\
(\%)\end{array}$} \\
\hline \multirow{3}{*}{$\begin{array}{c}\text { Nhóm } \\
\text { tuổi }\end{array}$} & $60-69$ & & \\
\hline & $70-79$ & 47 & 33,6 \\
\hline & $\geq 80$ & 35 & 25,0 \\
\hline \multirow{2}{*}{ Giới } & Nam & 17 & 12,1 \\
\hline & Nữ & 123 & 87,9 \\
\hline \multirow{3}{*}{$\begin{array}{l}\text { Hoàn cảnh } \\
\text { sống }\end{array}$} & Sống một mình & 10 & 7,1 \\
\hline & $\begin{array}{l}\text { Sống cùng } \\
\text { người thân }\end{array}$ & 130 & 92,9 \\
\hline & & $\begin{array}{l}\text { Trung } \\
\text { bình }\end{array}$ & $\begin{array}{l}\text { Đô lệch } \\
\text { chuẩn }\end{array}$ \\
\hline \multicolumn{2}{|c|}{ Tuối trung bình } & 73,2 & 9,0 \\
\hline
\end{tabular}

Tuổi trung bình của các đối tượng tham gia nghiên cứu là 73,2 $\pm 9,0$ tuổi. Tỷ lệ đối tượng nghiên cứu nằm trong độ tuổi từ 70 tuổi trở lên chếm $58,6 \%$.

Đa phần các đối tượng tham gia nghiên cứu có giới tính là nữ giới chiếm $87,9 \%$. Hầu hết các đối tượng nghiên cứu đang sống cùng người thân với 92,9\%.

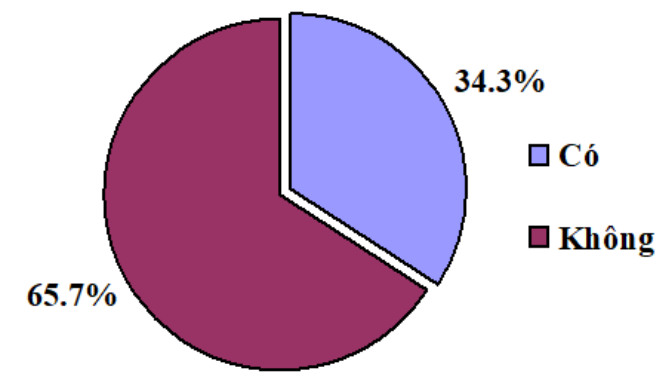

Biểu đồ 1: Tỷ lệ ngã ở đôîi tượng nghiên cúu $(N=140)$ 
Tỷ lệ ngã trên người cao tuổi có loãng xương là $34,3 \%(n=48)$.

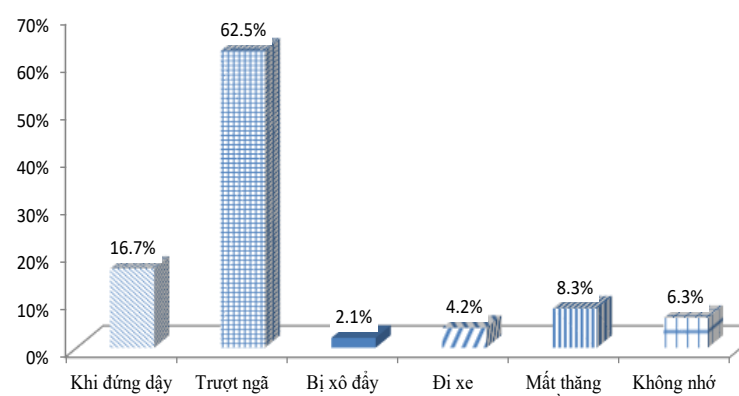

Biểu đồ 2: Hoàn cảnh ngã của đôî tượng nghiên cứu $(\mathbf{N}=48)$

Tỷ lệ người bệnh bị ngã trong hoàn cảnh bị trượt ngã chiếm tỷ lệ cao nhất với $62,5 \%$, tiếp theo là ngã khi đứng dây chiếm $16,7 \%$.

Bảng 2: Địa điểm ngã của đôi tượng nghiên cứlu $(\mathrm{N}=48)$

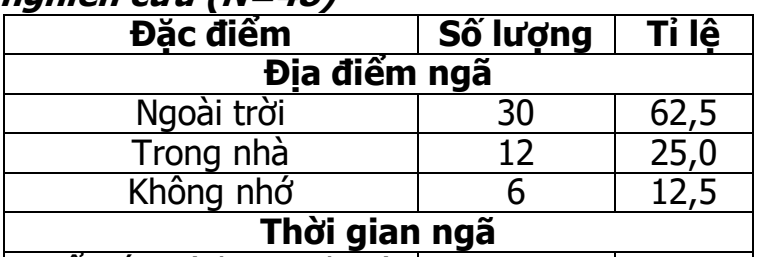

\begin{tabular}{|c|c|c|}
\hline Buối sáng (6h00-12h00) & 33 & 68,8 \\
\hline Ban chiêu (12h00-18h) & 5 & 10,4 \\
\hline Ban tối (18h00-6h00) & 7 & 14,6 \\
\hline Không nhớ & 3 & 6,3 \\
\hline
\end{tabular}

Biến chứng gãy xương

\begin{tabular}{|c|c|c|}
\hline Có gãy xương & 42 & 87,5 \\
\hline Không gãy xương & 6 & 12,5 \\
\hline
\end{tabular}

Có 62,5\% đối tượng nghiên cứu ngã ở ngoài trời. Thời gian ngã của người bệnh chủ yếu vào thời điểm buổi sáng với $68,8 \%$. Phần lớn đối tượng nghiên cứu có biến chứng gãy xương khi ngã với tỷ lệ $87,5 \%$.

Bảng 3: Ngã và một số yêu tố liên quan của đối tượng nghiên cứu (N=140)

\begin{tabular}{|c|c|c|c|c|}
\hline \multirow{2}{*}{\multicolumn{2}{|c|}{ Thông tin }} & \multicolumn{2}{|c|}{ Ngã } & \multirow[b]{2}{*}{$\mathbf{P}$} \\
\hline & & \multirow{2}{*}{\begin{tabular}{|c|}
$\begin{array}{c}\text { Có } \\
(\mathbf{n = 4 8 )}\end{array}$ \\
$18(31,0)$ \\
\end{tabular}} & \multirow{2}{*}{$\begin{array}{l}\begin{array}{l}\text { Không } \\
(\mathbf{n = 9 2})\end{array} \\
40(69,0) \\
\end{array}$} & \\
\hline \multirow{3}{*}{$\begin{array}{c}\text { Nhóm } \\
\text { tuổi }\end{array}$} & $60-69$ & & & \multirow{3}{*}{0.79} \\
\hline & $70-79$ & $17(36,2)$ & $30(63,8)$ & \\
\hline & $\geq 80$ & $13(37,1)$ & $22(62,9)$ & \\
\hline \multirow{2}{*}{ Giới } & Nam & $7(41,2)$ & $10(58,8)$ & \multirow{2}{*}{0,52} \\
\hline & Nũ̃ & $41(33,3)$ & $82(66,7)$ & \\
\hline \multirow{2}{*}{$\begin{array}{l}\text { Hoàn } \\
\text { cảnh } \\
\text { sống }\end{array}$} & $\begin{array}{l}\text { Sống một } \\
\text { minh }\end{array}$ & ,0) & 5 & \multirow{2}{*}{0,31} \\
\hline & $\begin{array}{l}\text { Sống cùng } \\
\text { con }\end{array}$ & $43(33,1)$ & $87(65,7)$ & \\
\hline
\end{tabular}

Không thấy sự khác biêt có ý nghĩa thống kê với $p>0,05$ giữa nhóm tuổi, giới tính và hoàn cảnh sống của người bệnh với ngã.

\section{BÀN LUẬN}

Kết quả nghiên cứu trên 140 người bệnh cao tuổi có loãng xương tại Bệnh viện Lão khoa Trung Ương trong thời gian từ tháng $07 / 2020$ tháng 05 năm 2021 với tuổi trung bình là 73,2 \pm 9,0 tuổi, tuổi thấp nhất là 60 tuổi, cao nhất là 96 tuổi. Phần lớn các đối tượng là nữ giới với tỷ lệ $87,9 \%$ và hấu hết đang sống chung cùng người thân với 92,9\%, tỷ lệ người bệnh có tiền sử bị ngã từ 60 tuổi trở lên là 34,3\%. Kết quả nghiên cứu này thấp hơn so với kết quả nghiên cứu của tác giả Raimunda Beserra Silva và cộng sự (2010) với tỷ lệ ngã ở nhóm phụ nữ có loãng xương là $51 \%$ [2]. Sự khác biệt này có thể là sự khác biệt về lựa chọn đối tượng nghiên cứu, bởi trong nghiên cứu của chúng tôi có người bệnh giới tính nam, còn Raimunda Beserra Silva [2] chỉ đánh giá trên đối tượng là phụ nữ mãn kinh.

Kết quả nghiên cứu của chúng tôi chưa cho thấy sự khác biệt có ý nghĩa thống kê giữa nhóm tuổi, hoàn cảnh sống của người cao tuổi với tỷ lệ ngã. Tuy nhiên các kết quả quan sát trong nghiên cứu của chúng tôi cũng tương tự như kết quả của nhiêu nghiên cứu khác cho thấy tỷ lệ ngã ở người già tăng theo tuổi, những người sống một mình có tỷ lệ ngã cao hơn so với những người sống cùng con cháu [4]. Nghiên cứu của chúng tôi không thấy có sự khác biệt có ý nghĩa thống kê về tỷ lệ ngã giữa giới tính của các đối tượng nghiên cứu mặc dù nữ giới thường được biết đến là có nguy cớ ngã cao hơn nam giới trong các nghiên cứu trên đối tượng người cao tuổi do sự suy giảm nồng độ estrogen sau tuổi mãn kinh đã làm tăng nguy cơ loãng xương ở nữ giới và tăng nguy cơ ngã [5].

Nghiên cứu về hoàn cảnh ngã ở những người bệnh có ngã cho thấy phần lớn đối tượng nghiên cứu bị ngã trong hoàn cảnh do trượt ngã với tỷ lệ $62,5 \%$. Kết quả nghiên cứu này của chúng tôi cũng tương tự như kết quả nghiên cứu của nhiều tác giả khác, cho thấy người bệnh ngã trong hoàn cảnh vấp và trượt ngã là khá phổ biến [6]. Địa điểm người bệnh ngã nhiều nhất trong nghiên cứu của chúng tôi là ngã ở ngoài trời với tỷ lệ $62,5 \%$. Theo Blake và cộng sự nghiên cứu trên 1042 người khỏe mạnh từ 65 tuổi trở lên cho thấy tỷ lệ ngã ở ngoài trời là $61,9 \%$ [7].

Thời gian ngã trong ngày trong nghiên cứu của chúng tôi phổ biến là vào thời điểm buổi sáng với 68,8\%. Tỷ lệ người bệnh ngã vào thời điểm buổi sáng nhiêu hơn trong nghiên cứu của chúng tôi có thể là do vào buổi sáng người bệnh 
khi người bệnh vừa trải qua một giấc ngủ dài, các cơ quan vân động chưa được thực hiện linh hoạt do vậy dễ khiến cho người bệnh vận động khó khăn hơn và mất thăng bằng hơn do vậy dề bị ngã hơn. Thời điểm ban tối, cũng là một yếu tố thuận lợi khiến cho người bệnh cao tuổi dể bị ngã, ở người cao tuổi do có sự suy giảm về thị lực vậy khi trời tối, người bệnh có thể sẽ khó khăn khi nhìn đường hay các chướng ngại vật trong quá trình di chuyển do vậy thời điểm ban tối cũng là thời điểm người bệnh rất dễ bị ngã.

Hậu quả của ngã ở người cao tuổi thường nghiêm trọng hơn nhiều so với người trẻ. Nghiên cứu của chúng tôi cho thây tỷ lệ đối tượng nghiên cứu có biến chứng gãy xương khi ngã là $87,5 \%$. Kết quả nghiên cứu này của chúng tôi cũng tương tự với một số các tác giả khác trên thế giới. Một nghiên cứu đánh giá có hệ thống về dịch tễ học về ngã và gãy xương do loãng xương của nhóm tác giả Alan Morrison và cộng sự (2013) cho thấy tỷ lệ gãy xương do loãng xương dao động từ $71,6 \%$ đến $92,4 \%$ ở tất cả các vị trí loãng xương trong dân số nghiên cứu chung. Trong đó tỷ lệ gãy xương do loãng xương ở nữ là 80 - 92,4\% còn ở nam giới là 71,6 $78,6 \%$ [8].

\section{KẾT LUÂ̂N}

Biến chứng gãy xương sau ngã chiếm tỷ lệ rất cao trên bệnh nhân cao tuổi có loãng xương. Cần tăng cường các biện pháp dự phòng ngã để giảm tỷ lệ ngã ở nhóm đối tượng này, góp phần giảm thiểu hậu quả do ngã trên người cao tuổi cũng như gánh nặng xã hội.

\section{TÀI LIÊU THAM KHẢO}

1. Fu D., Kalache A., Yoshida S.(2007), "WHO global report on falls prevention in older age". France: World Health Organization," France: World Health Organization.

2. Lúcia C.P, Raimunda B.D.S., Sirlei S.M., et al (2010), "Predictors of Falls in Women With and Without Osteoporosis", Journal of Orthopaedic \& Sports Physical Therapy, 40(9), tr. 582-588.

3. Wim V, Lankveld E.S., Roland L., et al (2011), "Does osteoporosis predispose falls? a study on obstacle avoidance and balance confidence", BMC Musculoskeletal Disorders 12.

4. Paek K.W., Cho J.P., Song H.J., et al (2001), "Prevalence and associated factors of falls in the elderly community", Korean J Prev Med, 34, tr. 47-54.

5. Cooper C., Gale C.R., Aihie S. (2016), "Prevalence and risk factors for falls in older men and women: The English Longitudinal Study of Ageing", Age Ageing, 46(6), tr. 789-794.

6. Meng-Meng H., Hong-Ying $P_{\text {., }}$ Jie Z Zh., et al (2015), "Circumstances of falls and fall-related injuries among frail elderly under home care in China," International Journal of Nursing Sciences ," 2(3), tr. 237-242.

7. Morgan K., Blake A.J., Bendall M.J., (1988), "Falls by elderly people at home: prevalence and associated factors", Age Ageing, 17(6), tr. 365-72.

8. Fan T., Morrison A., Sen S.S., Weisenfluh L. (2013), " Epidemiology of falls and osteoporotic fractures: a systematic review", Clinicoecon Outcomes Res, 5, tr. 9-18.

\section{KẾT QUẢ ĐÎ̀̂U TRI THOÁI HÓA KHỚP GỐI NGUYÊN PHÁT BẰNG LIÊUU PHÁP TIÊM NộI KHỚP ACID HYALURONIC KẾT HỢP SORBITOL}

\section{TÓM TẮT.}

Mục tiêu: Đánh giá kết quả và tác dung không mong muốn của liệu pháp tiêm nội khớp acid hyaluronic kết hợp sorbitoltrong điều trị thoái hóa khớp gối nguyên phát. Đối tượng và phương pháp: Nghiên cứu tiến cứu, can thiệp, có nhóm chứng, theo dỗi dọc trên 101 bệnh nhân với 151 khớp gối thoái hóa giai đoạn II, IIİ theo Kellgren và Lawrence, chia làm 2 nhóm: nhóm can thiệp được tiêm 1 ống Synolis

\footnotetext{
${ }^{1}$ Bệnh viện hữu nghị đa khoa Nghệ An, ${ }^{2}$ Trường Đại học Y Hà Nội Chịu trách nhiệm chính: Phạm Hoài Thu Email: phamhoaithu@hmu.edu.vn Ngày nhận bài: 12.7.2021 Ngày phản biện khoa học: 6.9.2021 Ngày duyệt bài: 13.9.2021
}

Nguyễn Thị Lý1, Nguyễn Thị Ngọc Lan², Phạm Hoài Thu ${ }^{2}$

VA 80/160mg vào khớp gối tổn thương, nhóm chứng được điêu trị bằng thuốc đường uống Mobic, Viatril $S$. Kết quả điều trị: Điểm VAS, WOMAC, biên độ gấp gối ở nhóm can thiệp có sự cải thiện rõ rệt bắt đâu từ tuân thứ 4 và tiếp tực cho đến tuần 12 , tốt hơn nhóm chứng có ý nghĩa thống kê $(\mathrm{p}<0,01)$. Sau 12 tuần điều trị,, điểm VAS giảm từ 5,28 xuống 1,24, tỷ lệ đau vữa/nặng giảm từ $100 \%$ xuống $6,8 \%$,có $39,2 \%$ không đau, điểm WOMAC chung giảm từ 36,46 xuống 12,27 , biên độ gấp khớp gối tăng them 19,46 $\pm 11,84$ độ, tỷ lệ hài lòng và rất hài lòng $92,3 \%(p<0,01)$. Không gắp tác dụng không mong muốn nghiêm trọng, 28,4\% cằng tức khớp gối sau tiêm,12,2\% đau sau tiêm trong vòng 12-24 giớ, $4,1 \%$ tràn dịch khớp. Kết luận: Liệu pháp tiêm nội khớp acid hyaluronic kết hợp sorbitolcó tác dụng giảm đau nhanh, cải thiện chức năng vận động của khớp gối tốt hơn nhóm chứng và có tính an toàn.

Tư khóa: Thoái hóa khớp gối nguyên phát, Synolis VA, acid hyaluronic, sorbitol. 